\title{
Blutzuckertest in Tränen statt Blutstropfen
}

\author{
Wissenschaftler der University of Michigan in Ann Arbor (USA) haben ein Gerät \\ entwickelt, das erlaubt, mit einem elektrochemischen Sensor Zuckerwerte \\ in der Tränenflüssigkeit statt im Blut zu messen. Damit könnte der Tag näher \\ rücken, an dem 350 Millionen Diabetikern das lästige und schmerzhafte \\ Stechen zur Blutzuckerkontrolle erspart wird.
}

- Ein amperometrischer, nadelförmiger, elektrochemischer Glukosesensor wird benutzt in Verbindung mit einer $0,84 \mathrm{~mm}$ weiten Kapillare, die die lVolumina der Tränenflüssigkeit sammelt. Der Sensor basiert auf immobilisierter Glukoseoxidase auf einem dünnem $\mathrm{Pt} /$ Ir-Draht. Durch die Enzymreaktion wird $\mathrm{H}_{2} \mathrm{O}_{2}$ freigesetzt, dessen Konzentration mit dem Sensor gemessen werden kann.

Der Sensor ist so optimiert, dass er $1,5 \pm 0,4 \mu \mathrm{Mol}$ Glukose nachweisen kann. Das Gerät erreicht damit eine Glukoseempfindlichkeit von $0,032 \pm 0,2$
nA/ $\mu$ Mol. Nur 4-5 $\mu$ l Tränenflüssigkeit sind für eine Messung erforderlich.

In einer Pilotstudie wurden Glukosemessungen über acht Stunden an anästhesierten Kaninchen vorgenommen. Zwischen den Glukosewerten in der Tränenflüssigkeit und im Blut bestand eine hohe Übereinstimmung.

Der Vorschlag, die Glukose in der Tränenflüssigkeit zu bestimmen, wurde erstmals in den 1950er Jahren gemacht. Die Umsetzung dieser Idee ist bisher am Fehlen ausreichend sensibler Messsensoren gescheitert.

\section{Kommentar}

Die Glukosemessungen in der Tränenflüssigkeit sind eine potenzielle nicht invasive Ergänzung zu den klassischen Blutglukosemessungen. Neue Sensorentwicklungen könnten die Methode weiter verfeinern..

K. MALBERG

- Q. Yan et al.

(Korrespondenzadresse: Eye Group, LLC 2350 Washtenaw Ave, Ann Arbor, MI 48104, USA; e-mail: mmeyerhof@umich.edu) Measurement of tear glucose levels with amperometric glucose biosensor/capillary tube configuration. Anal. Chem. 2011; 83:8341-46; doi: 10.1021/ ac201700a

\section{Darmkrebs durch Mikroben ausgelöst?}

\begin{abstract}
Bakterien der Gattung Fusobakterium kommen in Darmtumoren häufiger vor als in gesundem Darmgewebe. Das könnte ein Hinweis sein, dass möglicherweise bakterielle Infektionen Darmkrebs hervorrufen oder zumindest begünstigen können.
\end{abstract}

- Zwei Wissenschaftlergruppen am Dana Farber Cancer Institute der University in Boston (USA) und an der University of British Columbia in Vancouver (Kanada) fanden mit zwei verschiedenen Methoden der quantitativen PCR 100 mal höhere Konzentrationen an Fusibakterium-DNA im Tumorgewebe. Andere Mikroben-DNA kam seltener vor.

- M. Meyerson et al Genomic analysis identifies association of Fusobacterium with colorectal carcinoma. Fusobacterum nucleatum infection is prevalent in human colorectal carcinoma. Published in Advance October 18, 2011: doi:10.1101/ (gr.126573.111 Genome Res. 2011

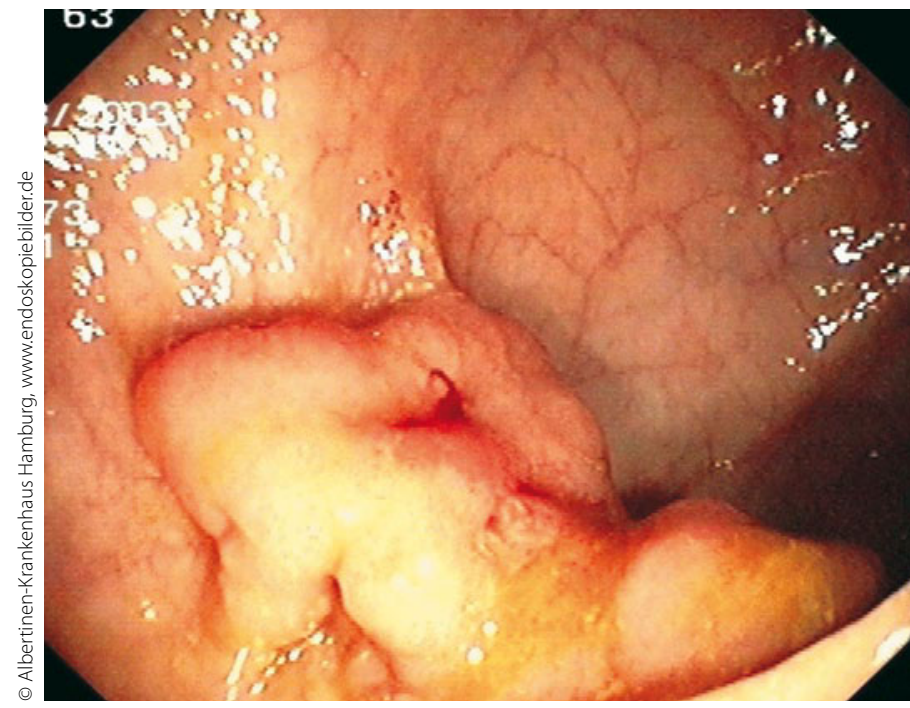

Kolonkarzinom: hohe Konzentrationen an bakterieller DNA im Gewebe.
Kommentar

Von Fusobakterien ist bekannt, dass sie an chronischen Darminfektionen beteiligt sind und so ein Risikofaktor für Darmkrebs sein können. Es ist aber unklar, ob sie Ursache oder Folge einer Krebserkrankung sind.

K. MALBERG 